\title{
Oxygen and Nitrate New Production and Remineralization in the North Atlantic Subtropical Gyre
}

\author{
Jorge L. Sarmiento, ${ }^{1}$ Gerhard Thiele, ${ }^{2}$ Robert M. Key, ${ }^{1}$ and Willard S. Moore ${ }^{3}$
}

\begin{abstract}
New estimates are obtained of oxygen utilization rates on isopycnal surfaces in the North Atlantic subtropical gyre thermocline based on tritium inventories $\left(2.4-3.5 \mathrm{~mol} \mathrm{~m}^{-2} \mathrm{yr}^{-1}\right)$ and ${ }^{228} \mathrm{Ra}$ measurements $\left(8.5 \pm 0.8 \mathrm{~mol} \mathrm{~m}^{-2} \mathrm{yr}^{-1}\right)$. Arguments are given for why the tritium inventory oxygen utilization rate estimate may be too low. The ${ }^{228} \mathrm{Ra}$ results are combined with recent estimates of oxygen utilization within the thermocline (Jenkins, 1987) as well as estimates of oxygen production in the mixed layer (Spitzer and Jenkins, 1989; Musgrave et al., 1988), to suggest a tentative overall oxygen balance for the whole water column. The new production of oxygen in the surface ocean $(\sim 4.6$ $\left.\pm 1.6 \mathrm{~mol} \mathrm{~m}^{-2} \mathrm{yr}^{-1}\right)$ appears to be lower than the estimated utilization within the thermocline $(\sim 8.5$ $\pm 0.8 \mathrm{~mol} \mathrm{~m}^{-2} \mathrm{yr}^{-1}$ ), suggesting that there may be a net lateral import of organic matter into the thermocline equivalent to a new production of $-3.9 \pm 1.8 \mathrm{~mol} \mathrm{~m}^{-2} \mathrm{yr}^{-1}$. The nitrogen balance is consistent with these results. An estimate for the total nitrogen remineralization rate in the thermocline is obtained from the oxygen utilization rate by using an $-\mathrm{O}_{2}: \mathrm{N}$ Redfield ratio of $9.1 \pm 0.4$ for remineralization (Minster and Boulahdid, 1987), giving a nitrogen remineralization rate of $\sim 0.93 \pm$ $0.10 \mathrm{~mol} \mathrm{~m}^{-2} \mathrm{yr}^{-1}$. Subtracting off the estimated lateral export of nitrate of $\sim 0.51 \pm 0.21 \mathrm{~mol} \mathrm{~m}^{-2}$ $\mathrm{yr}^{-1}$, which is presumed to be balanced by a lateral import of dissolved organic nitrogen (Rintoul and Wunsch, 1990), gives a nitrate flux into the surface of $\sim 0.42 \pm 0.23 \mathrm{~mol} \mathrm{~m}^{-2} \mathrm{yr}^{-1}$, which is comparable to the estimate of $0.6 \pm 0.2 \mathrm{~mol} \mathrm{~m}^{-2} \mathrm{yr}^{-1}$ obtained by Jenkins (1988) near Bermuda as well as the $100-\mathrm{m}$ particulate nitrogen flux of $0.33 \mathrm{~mol} \mathrm{~m}^{-2} \mathrm{yr}^{-1}$ obtained Altabet (1989) near Bermuda.
\end{abstract}

\section{INTRODUCTION}

The distribution of nonanthropogenic $\mathrm{CO}_{2}$ between the ocean and atmosphere is affected strongly by the cycling of carbon by organisms within the water column. Primary production is the removal of dissolved inorganic $\mathrm{CO}_{2}$ and nutrients from the euphotic region by photosynthesis, which converts them into particulate and dissolved organic matter and releases oxygen. Most of the organic matter thus produced is recycled by organisms within the euphotic zone (regenerated production). The remaining highly variable and rather poorly known fraction of order 30\% [Platt et al., 1989] manages to escape to the thermocline and abyssal waters. There it is remineralized by metabolic processes which convert organic matter back to dissolved inorganic $\mathrm{CO}_{2}$, $\mathrm{PO}_{4}^{-3}$, and $\mathrm{NO}_{3}^{-1}$, consuming oxygen in the process. This export of organic matter from the surface is commonly referred to as new production. It must, on the average, be balanced by a net import of new inorganic $\mathrm{CO}_{2}$, nitrate, and phosphate from below, as well as an export of oxygen to the atmosphere by gas exchange and to the thermocline by vertical exchange processes. There is also a relatively minor input from rivers and the atmosphere, which we ignore in the following discussion. One can readily infer from the above that the oceanic $\mathrm{CO}_{2}$, oxygen, and nutrient cycles will be out of balance unless the new production at the surface is equal to the integrated remineralization below the surface when

\footnotetext{
${ }^{1}$ Atmospheric and Oceanic Sciences Program and Department of Geology and Geophysics, Princeton University, Princeton, New Jersey.

${ }^{2}$ Deutsche Forschungs- und Versuchasanstalt für Luft- und Raumfahrt, Astronautenburo, Linder Hohe, Cologne, Federal Republic of Germany.

${ }^{3}$ Department of Geology, University of South Carolina, Colum-
}

Copyright 1990 by the American Geophysical Union.

Paper number $90 \mathrm{JC} 01049$

0148-0227/90/90JC-01049\$05.00 averaged over sufficient time and space to remove seasonal, interannual, and spatial variability.

The new production is a quantity of great interest for a variety of reasons, not the least of them being that it is the major mechanism by which the surface ocean and atmospheric $\mathrm{CO}_{2}$ contents are maintained at levels approximately a factor of 2 lower than would be the case otherwise. Furthermore, the significantly lower atmospheric $\mathrm{CO}_{2}$ content observed during the last ice age may have been caused by an increase in the efficiency of $\mathrm{CO}_{2}$ removal by new production relative to the supply of $\mathrm{CO}_{2}$-enriched waters by vertical exchange in high-latitude deep water formation regions [Sarmiento and Toggweiler, 1984; Siegenthaler and Wenk, 1984; Knox and McElroy, 1984] (Sarmiento et al. [1988] give a recent overview of this and related topics). This mechanism could conceivably play a role in determining the near-future atmospheric $\mathrm{CO}_{2}$ content in response to the fossil $\mathrm{CO}_{2}$ transient as well.

Platt et al. [1989] and Eppley [1989] recently reviewed the problem of determining oceanic new production. Biological oceanographers commonly make use of techniques based on in vitro incubations to estimate the new production from measurements of the photosynthetic uptake of nitrate using the isotope ${ }^{15} \mathrm{~N}$ as a tracer. Ammonium and nitrate uptake are thought to be related directly to regenerated production and new production, respectively. This approach has numerous difficulties [cf. Platt et al., 1989]. One of the greatest of these, which is relevant to estimating an overall steady state balance, is the problem of obtaining long-term averages. In vitro measurements have an intrinsic time scale of only a few hours. Models and observations suggest considerable variability of the new production.

An alternative to the above approach is to find the new production or remineralization rate as a residual of the nutrient transport terms. The divergence of advective and diffusive transport is equal to the new production or remineralization plus the time rate of change of nutrient concentration. Another alternative is to use tracers to give a 
measure of time over which a change in nutrient concentration due to new production or remineralization occurs. The time scale of such estimates can be seasonal, annual, or even longer. This gives some hope of obtaining an overall steady state balanced budget for the various constituents involved in biological cycling. Riley [1951] was perhaps the first to try this approach. He estimated the regeneration rate in the Atlantic main thermocline based on a geostrophic velocity and mixing model of the oxygen transport. Rintoul and Wunsch [1990] recently carried out a study in the North Atlantic subtropical gyre of the nutrient balance which used the same basic approach but with a more rigorous estimate of the transport terms. Jenkins [1977, 1980, 1982a, 1987] carried out a series of studies giving estimates of the oxygen utilization rates (OUR) at several locations in the North Atlantic based on tritium and helium 3 observations. There are, in addition, numerous other estimates of new production based primarily on surface mixed layer tracer observations and transport divergence calculations [e.g., Shulenberger and Reid, 1981; Jenkins and Goldman, 1985; Lewis et al., 1986; Peng et al., 1987; Emerson, 1987; Musgrave et al., 1988; Jenkins, 1988b; Spitzer and Jenkins, 1989].

Sediment trap data [e.g., Martin et al., 1987] give an estimate of the new production removed by larger particles. However, it appears likely that sediment traps catch only a portion of the new production in many regions of the ocean. The flux of new production out of the surface by smaller suspended particles not caught by traps has been shown in at least one case (at Bermuda) to be more than $50 \%$ of the large particle flux [Altabet, 1989]. Furthermore, there is increasing evidence from both measurements and models that a large fraction of the flux of new production out of the surface may be as dissolved organic matter [e.g., Suzuki et al., 1985; Sugimura and Suzuki, 1988; Sarmiento et al., 1988; Toggweiler, 1988, 1989; Williams and Druffel, 1988; Najjar, 1990; Rintoul and Wunsch, 1990].

The purpose of this paper is to present two new estimates of the OUR in the North Atlantic main thermocline based on tritium inventories and ${ }^{228} \mathrm{Ra}$ measurements. These new estimates are combined with previous work from the same region to construct a tentative oxygen and nitrate cycling budget. One of the major challenges is to reconcile the widely divergent estimates obtained by different techniques.

\section{OUR ESTIMATES}

We begin by discussing the box model approach used to estimate OUR from tritium inventories. This is followed by the derivation of a set of "age" equations based on apparent oxygen utilization (AOU, defined as the saturation oxygen concentration at the potential temperature of a given water parcel minus the observed concentration) and ${ }^{228} \mathrm{Ra}$. The equations illustrate the relationship between $\mathrm{AOU},{ }^{228} \mathrm{Ra}$, age, and OUR. We also show the analogy between our approach and the tritium and helium 3 age approach first used by Jenkins [1982a].

\subsection{Tritium Box Modeling Approach and OUR Estimates}

Sarmiento [1983] developed the box model illustrated in Figure 1 in order to study the exchange of thermocline waters with surface waters, i.e., "ventilation," using tritium inventories as a constraint. The box model equation is

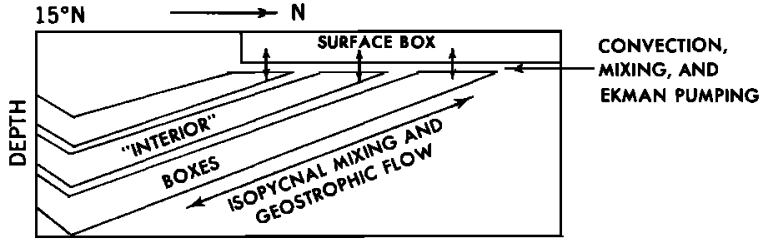

Fig. 1. A schematic depiction of the tritium box model. Mechanisms of exchange between the surface and interior boxes and of spreading on interior boxes are suggested. Taken from Sarmiento [1983].

$$
\frac{\partial T_{I}}{\partial t}=\frac{1}{\tau_{\text {box }}}\left(T_{s}-T_{I}\right)-\lambda_{\mathrm{T}} T_{I}
$$

where $T_{I}$ is the average concentration in the interior box (essentially a measure of the inventory), $T_{s}$ is the concentration at the surface given by Dreisigacker and Roether [1978] , and $\tau_{\text {box }}$ is the "ventilation" time, which represents the effect of advective, diffusive, and convective exchange between the thermocline and surface waters. Jenkins [1980] used essentially the same approach to find ventilation time scales from tritium and helium 3 measurements in the Sargasso Sea, assuming that the few measurements he had were representative of the entire recirculation region.

Table 1 shows the $\tau_{\text {box }}$ values calculated by Sarmiento [1983] using mid-1971 to mid-1973 North Atlantic tritium observations (see Sarmiento et al. [1982] for a discussion of the data set used to calculate the inventories). The thermocline is represented by a stack of boxes defined by constant potential density surfaces of thickness $\Delta \sigma_{\theta}=0.1$ centered on $\sigma_{\theta}=26.2$ to 27.4 in the region between $15^{\circ} \mathrm{N}$ and the wintertime outcrops determined from the data of Levitus [1982]. The average depths of the density surfaces, shown in Table 1, lie between 140 and $696 \mathrm{~m}$, with the northernmost outcrop occurring at $\sim 55^{\circ} \mathrm{N}$. The tritium data indicate that exchange across $\sim 15^{\circ} \mathrm{N}$ is very slow [Sarmiento et al., 1982]. This is approximately the boundary between the "ventilated thermocline" to the north and poorly ventilated "shadow zone" to the south, concepts that were first introduced by the theoretical studies of Luyten et al. [1983]. Diapycnal exchange is also thought to make a negligible

TABLE 1. OUR Calculated From Tritium Inventory

\begin{tabular}{|c|c|c|c|c|}
\hline$\sigma_{\theta}$ & Mean Depth, m & $\begin{array}{c}\mathrm{AOU}^{*} \\
\mu \mathrm{mol} \mathrm{kg}\end{array}$ & $\tau$, years & $\begin{array}{c}\text { OUR, } \\
\mu_{\mathrm{yr}^{-\mathrm{I}}}\end{array}$ \\
\hline 26.2 & 140 & 21.4 & 7.2 & 3.0 \\
\hline 26.3 & 153 & 25.4 & 7.3 & 3.5 \\
\hline 26.4 & 175 & 28.1 & 7.5 & 3.7 \\
\hline 26.5 & 210 & 33.3 & 8.2 & 4.1 \\
\hline 26.6 & 255 & 41.7 & 9.3 & 4.5 \\
\hline 26.7 & 299 & 51.0 & 10.7 & 4.8 \\
\hline 26.8 & 339 & 60.6 & 12.3 & 4.9 \\
\hline 26.9 & 381 & 69.2 & 13.7 & 5.1 \\
\hline 27.0 & 428 & 78.1 & 14.6 & 5.3 \\
\hline 27.1 & 476 & 87.0 & 16.1 & 5.4 \\
\hline 27.2 & 540 & 96.9 & 19.1 & 5.0 \\
\hline 27.3 & 614 & 105.6 & 28.9 & 3.7 \\
\hline 27.4 & 696 & 109.8 & 38.8 & 2.8 \\
\hline
\end{tabular}

${ }^{*} \mathrm{AOU}_{\mathrm{S}}$ is assumed to be $0 \mu \mathrm{mol} \mathrm{kg}{ }^{-1}$. 
contribution on the time scale of the tritium transient [e.g., Jenkins, 1980].

The AOU equation for the box model has the same form as (1) with $-\lambda_{\mathrm{T}} T_{I}$ replaced by + OUR.

$$
\frac{\partial \mathrm{AOU}_{I}}{\partial t}=\frac{1}{\tau_{\text {box }}}\left(\mathrm{AOU}_{s}-\mathrm{AOU}_{I}\right)+\mathrm{OUR}
$$

Assuming that $\partial \mathrm{AOU}_{l} / \partial t=0$, gives

$$
\text { OUR }=\left(\mathrm{AOU}_{I}-\mathrm{AOU}_{s}\right) / \tau_{\text {box }}
$$

This equation is used to find an average interior OUR from observations of AOU and the tritium box model $\tau_{\text {box }}$ values. The results are given in Table 1. Equation (2) is equivalent to that used by Jenkins [1980].

\subsection{Age Equation Derived From Oxygen Conservation}

The oxygen conservation equation in terms of $\mathrm{AOU}$ is

$$
d \mathrm{AOU} / d t=\nabla \cdot(\mathrm{K} \nabla \mathrm{AOU})+\mathrm{OUR}
$$

where $d \mathrm{AOU} / d t$ is the total derivative, including the advection terms, and $K$ is the diffusion tensor. If OUR is assumed to be constant on isopycnal surfaces within the region under consideration and diapycnic processes are ignored, one can divide through by OUR to obtain

$$
d \tau_{\mathrm{O}_{2}} / d t=\nabla_{h} \cdot\left(\mathrm{K} \nabla_{h} \tau_{\mathrm{O}_{2}}\right)+1
$$

where

$$
\tau_{\mathrm{O}_{2}}=\mathrm{AOU} / \mathrm{OUR}
$$

is a measure of the time since last contact with the surface. Only the along isopycnal terms are included for $\nabla_{h}$ and $d() / d t$. Changes in isopycnal thickness hảve been ignored. This age tracer has a source, the +1 term, that is linear with time (i.e., $\tau_{\mathrm{O}_{2}}$ increases linearly with $t$ ). Age defined this way therefore mixes conservatively. We shall see below that radioactive tracers, because they decrease exponentially with time due to decay, define an age which does not mix conservatively. Equation (4) thus defines an ideal tracer of age since last contact with the surface against which the ages determined by other tracers can be compared (see Thiele and Sarmiento [1990] for a discussion of this concept).

\subsection{Radium 228 Age Equation and OUR Estimates}

The ${ }^{228} \mathrm{Ra}$ equation

$$
d^{228} \mathrm{Ra} / d t=\nabla \cdot\left(\mathrm{K} \nabla{ }^{228} \mathrm{Ra}\right)-\lambda_{\mathrm{Ra}}{ }^{228} \mathrm{Ra}
$$

can also be cast in terms of an age since last contact with the surface by using the decay equation to define

$$
\tau_{\mathrm{Ra}}=\left[\ln \left({ }^{228} \mathrm{Ra}_{s} /{ }^{228} \mathrm{Ra}\right)\right] / \lambda_{\mathrm{Ra}}
$$

where ${ }^{228} \mathrm{Ra}_{s}$ is the ${ }^{228} \mathrm{Ra}$ concentration at the surface and $\lambda_{\mathrm{Ra}}=3.82 \times 10^{-9} \mathrm{~s}^{-1}$ is the ${ }^{228} \mathrm{Ra}$ decay constant. Equation (7) is solved for ${ }^{228} \mathrm{Ra}$ and substituted into (6) to obtain

$$
d \tau_{\mathrm{Ra}} / d t=\nabla \cdot\left(\mathrm{K} \nabla \tau_{\mathrm{Ra}}\right)+1-\lambda_{\mathrm{Ra}} \mathrm{K}\left(\nabla \tau_{\mathrm{Ra}}\right)^{2}
$$

This equation is identical to (4), i.e., $\tau_{\mathrm{Ra}}=\tau_{\mathrm{O}_{2}}$, if $\lambda_{\mathrm{Ra}}$ $\mathrm{K}\left(\nabla \tau_{\mathrm{Ra}}\right)^{2}$ is negligible. In such a case, and if the boundary conditions for $\tau_{\mathrm{O}_{2}}$ and $\tau_{\mathrm{Ra}}$ are identical, we can substitute $\tau_{\mathrm{O}_{2}}$ from (7) into (5) to obtain

$$
{ }^{228} \mathrm{Ra}={ }^{228} \mathrm{Ra}_{s} e^{-\lambda\left(\mathrm{AOU}-\mathrm{AOU}_{s}\right) / \mathrm{OUR}}
$$

Are the boundary conditions for $\tau_{\mathrm{O}_{2}}$ and $\tau_{\mathrm{Ra}}$ identical? Both ages are defined with respect to the concentration of the respective tracer at the surface of the ocean, from whence it is presumed that the tracer enters the thermocline. In fact, the major source of radium 228 to the surface ocean is continental shelf sediments, particularly (in the case of the North Atlantic) the North American shelf. However, maps of the distribution of radium 228 on isopycnal surfaces which we are preparing for publication suggest that radium 228 enters the thermocline through the same pathway as the oxygen, i.e., primarily from the northeast [Sarmiento et al., 1982]. In support of this, measurements of radium 228 and $\mathrm{O}_{2}$ north of the Gulf Stream, on the shallower density surfaces which have high-shelf radium 228 input, fall well above the trend of the radium 228 versus AOU plots in Figure 2. This suggests little direct interaction between shelf and thermocline waters. We believe that the major pathway for entry of North American shelf radium 228 into the thermocline is by advection around the edge of the subtropical gyre and spreading at the surface, followed by subduction by the same mechanisms that bring oxygen down from the surface.

Figure 2 shows least squares fits of (9) to the Transient Tracers in the Oceans (TTO) North Atlantic Study data reported by Key et al. [1985] as well as additional results from the TTO Tropical Atlantic Study (see Brewer et al. [1985] for station locations) and measurements made on three 1986 sections across the Gulf Stream at approximately $32^{\circ} \mathrm{N} 73^{\circ} \mathrm{W}$ to $34^{\circ} \mathrm{N} 76^{\circ} \mathrm{W}, 35^{\circ} \mathrm{N} 71^{\circ} \mathrm{W}$ to $38^{\circ} \mathrm{N} 74^{\circ} \mathrm{W}$, and $34^{\circ} \mathrm{N}$ $63^{\circ} \mathrm{W}$ to $43^{\circ} \mathrm{N} 64^{\circ} \mathrm{W}$, as well as a section between $34^{\circ} \mathrm{N} 63^{\circ} \mathrm{W}$ and $32^{\circ} \mathrm{N} 73^{\circ} \mathrm{W}$, all as part of a tracer study of western boundary exchange. Data south of $15^{\circ} \mathrm{N}$, shoreward of the Gulf Stream, north of the wintertime outcrop of the density surface, or having negative AOU values are excluded. The OURs thus obtained are given in Table 2 . The ${ }^{228} \mathrm{Ra}_{s}$ values given in the table are the intercept values (at $\mathrm{AOU}=0$ ). They are all in the range of observed concentrations at the surface.

\subsection{Tritium and Helium 3 Age Equation}

Jenkins [1987] has taken the tritium and helium 3 conservation equations

$$
\begin{gathered}
d T / d t=\nabla \cdot(\mathrm{K} \nabla T)-\lambda_{\mathrm{T}} T \\
d^{3} \mathrm{He} / d t=\nabla \cdot\left(\mathrm{K} \nabla{ }^{3} \mathrm{He}\right)+\lambda_{\mathrm{T}} T
\end{gathered}
$$

with an age defined as

$$
\tau_{\mathrm{THe}}=\left\{\ln \left[\left(T+{ }^{3} \mathrm{He}\right) / T\right]\right\} / \lambda_{\mathrm{T}}
$$

to obtain

$$
\begin{aligned}
d \tau_{\mathrm{THe}} / d t=\nabla \cdot\left(\mathrm{K} \nabla \tau_{\mathrm{THe}}\right) & +1 \\
& +\mathrm{K} \nabla \ln \left[T\left(T+{ }^{3} \mathrm{He}\right)\right] \nabla \tau_{\mathrm{THe}}
\end{aligned}
$$

The equation obtained by assuming that the final term in (13) is negligible gives (4), in which case we can use $\tau_{\mathrm{THe}}$ as a 


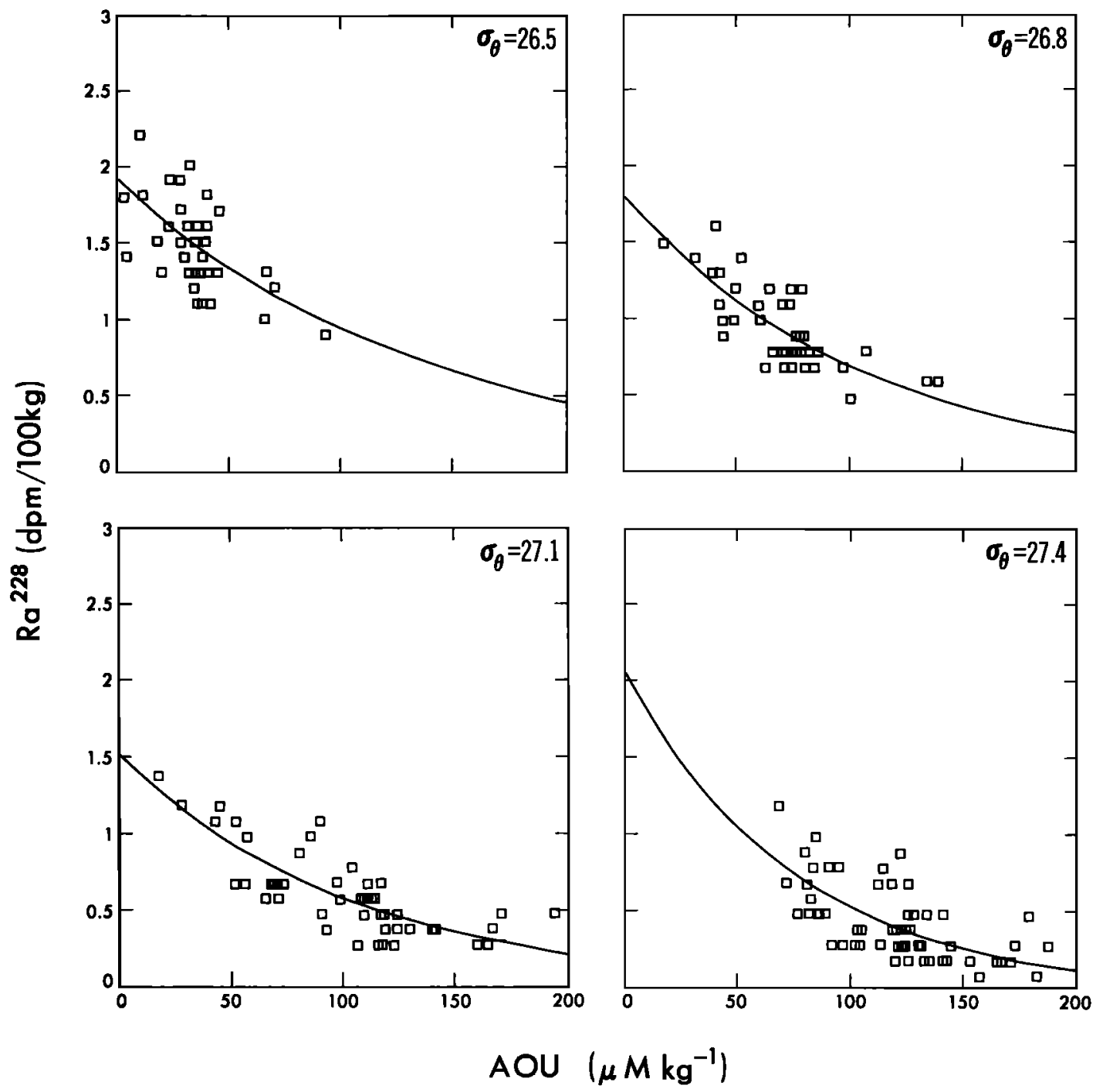

Fig. 2. Radium 228 as a function of apparent oxygen utilization (AOU) for four $\sigma_{\theta}$ surfaces in the North Atlantic. The solid curves represent the best line fit using the simple model given in the text.

proxy for $\tau_{\mathrm{O}_{2}}$ in (5) in order to obtain OUR, as long as the boundary conditions for both are the same. This is essentially the approach that Jenkins has followed in his estimates of OUR at the Beta Triangle site centered on $54^{\circ} \mathrm{S}$ and $45^{\circ} \mathrm{N}$

TABLE 2. OUR Calculated From Radium 228 Age

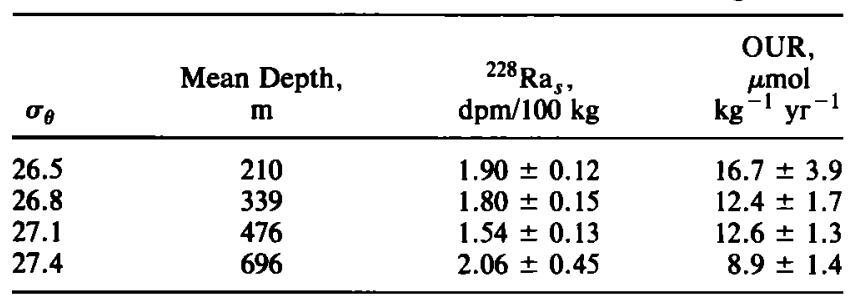

Due to the limited vertical resolution of ${ }^{228} \mathrm{Ra}$ measurements we did not calculate OUR on more than just the isopycnal surfaces given in the table. The fits were made using the nonlinear least squares fitting technique of Wolberg [1967]. AOUs were assumed to have a $4 \mu \mathrm{mol} \mathrm{kg}{ }^{-1}$ error, and ${ }^{228} \mathrm{Ra}$ values either a $0.1 \mathrm{dpm} / 100 \mathrm{~kg}$ error or a $15 \%$ error, with no significant difference in the results. Table 2 and Figure 2 show results from the calculation with a 0.1 $\mathrm{dpm} / 100 \mathrm{~kg}$ error. All data were linearly interpolated to the respective potential density surfaces.
[Jenkins 1982a, 1987] and shows that our work with ${ }^{228} \mathrm{Ra}$ is directly analogous.

\section{Discussion}

Table 3 summarizes all the oxygen and nitrate based new production and remineralization estimates for the North Atlantic of which we are aware. The remineralization estimates of Jenkins and Goldman [1985] and Lewis et al. [1986] are not included because the former is based on an extrapolation of estimates of oxygen loss over only a portion of the year and the latter is based on only 2 weeks worth of measurements.

There are a number of relatively large differences in the estimates in Table 3, particularly among the thermocline remineralization estimates calculated by us from the OURs in Figure 3 which are shown in the upper part of Table 3. The OURs in Figure 3 tend to fall into two groups: (1) the Jenkins [1987] Beta Triangle estimates and our ${ }^{228}$ Ra-based estimates are generally higher than (2) the box model estimates of Jenkins [1980] and our own tritium-inventory-based box 
TABLE 3. New Production and Remineralization Estimates in the North Atlantic

\begin{tabular}{|c|c|c|c|c|}
\hline Source & Technique & Region & $\begin{array}{l}\text { Depth } \\
\text { Range, } m\end{array}$ & $\begin{array}{l}\text { New Production } \\
\text { or } \\
\text { Remineralization, } \\
\text { mol m }^{-2} \mathrm{yr}^{-1}\end{array}$ \\
\hline \multicolumn{5}{|c|}{ Oxygen-Based Remineralization Rates* } \\
\hline Riley [1951] & $\begin{array}{l}\text { Geostrophic transport and } \\
\text { mixing model }\end{array}$ & $54^{\circ} \mathrm{S}$ to $45^{\circ} \mathrm{N}$ & $100-750$ & $2.5(1.6$ to 3.1$)$ \\
\hline $\begin{array}{l}\text { Jenkins }[1980] \\
\text { Jenkins }[1987]\end{array}$ & $\begin{array}{l}\text { Tritium } /{ }^{3} \text { He box model } \\
\tau_{\mathrm{THe}} \text { versus AOU } \\
\text { regression }\end{array}$ & $\begin{array}{l}\text { Sargasso Sea } \\
\text { Beta Triangle } \\
\quad\left(\sim 30^{\circ} \mathrm{N} 30^{\circ} \mathrm{W}\right)\end{array}$ & $\begin{array}{l}100-750 \\
100-750\end{array}$ & $\begin{array}{c}7.2 \\
6.4 \pm 0.3\end{array}$ \\
\hline This study & Tritium box model & $\begin{array}{l}15^{\circ} \mathrm{N} \text { to } \sigma_{\theta}=27.45 \\
\text { outcrop }\end{array}$ & $100-750$ & $2.8(2.4$ to 3.5$)$ \\
\hline This study & Radium-228 & $\begin{array}{l}15^{\circ} \mathrm{N} \text { to } \sigma_{\theta}=27.45 \\
\text { outcrop }\end{array}$ & $100-750$ & $8.5 \pm 0.8$ \\
\hline \multicolumn{5}{|c|}{ Mixed Layer Oxygen New Production Rates } \\
\hline Peng et al. [1987] & $\begin{array}{l}\mathrm{O}_{2} \text { production in mixed } \\
\text { layer }\end{array}$ & $64^{\circ} \mathrm{N} 28^{\circ} \mathrm{W}$ & & 5.1 \\
\hline Musgrave [1989] & $\begin{array}{l}\text { Upper ocean } \mathrm{O}_{2} \text { balance } \\
\text { model }\end{array}$ & $\begin{array}{l}\text { near Bermuda } \\
\left(32^{\circ} \mathrm{N} 64^{\circ} \mathrm{W}\right)\end{array}$ & & $3-4$ \\
\hline $\begin{array}{l}\text { Spitzer and Jenkins } \\
{[1989] \dagger}\end{array}$ & $\begin{array}{l}\text { Upper ocean } \mathrm{O}_{2} \text { balance } \\
\text { model }\end{array}$ & $\begin{array}{r}\text { near Bermuda } \\
\left(32^{\circ} \mathrm{N} 64^{\circ} \mathrm{W}\right)\end{array}$ & & $5.6 \pm 1.5$ \\
\hline \multicolumn{5}{|c|}{ Nitrogen Balance Estimates } \\
\hline Jenkins $[1988 b]$ & $\begin{array}{l}\text { Model of nitrate supply to } \\
\text { mixed layer }\end{array}$ & $\begin{array}{l}\text { near Bermuda } \\
\left(32^{\circ} \mathrm{N} 64^{\circ} \mathrm{W}\right)\end{array}$ & mixed layer & $0.6 \pm 0.2$ \\
\hline Altabet [1989] & $\begin{array}{l}\text { Particulate nitrogen flux } \\
\text { estimate }\end{array}$ & $\begin{array}{l}\text { near Bermuda } \\
\left(32^{\circ} \mathrm{N} 64^{\circ} \mathrm{W}\right)\end{array}$ & at $100 \mathrm{~m}$ & 0.33 \\
\hline $\begin{array}{l}\text { Rintoul and Wunsch } \\
{[1990] \ddagger}\end{array}$ & Model of $\mathrm{NO}_{3}$ transport & $24^{\circ} \mathrm{N}$ to $36^{\circ} \mathrm{N}$ & $\begin{array}{l}\text { whole water } \\
\text { column }\end{array}$ & $-0.51 \pm 0.21$ \\
\hline
\end{tabular}

*All the remineralization rates in this portion of the table are calculated by us from the raw OUR results given in the various papers and shown in Figure 3. The oxygen utilization rate of $5.7 \pm 0.5 \mathrm{~mol} \mathrm{~m}^{-2} \mathrm{yr}^{-1}$ obtained by Jenkins [1982a] is not included in the table since it is based on a collection of OURs obtained in several different regions with different techniques, all of which have been included in the table.

$\dagger$ Jenkins and Goldman [1985] made an earlier oxygen utilization rate estimate of $\sim 5 \mathrm{~mol} \mathrm{~m}^{-2} \mathrm{yr}^{-1}$ for the same location, but with a cruder approach and less data constraints. Part of the reason for the difference between the Spitzer and Jenkins [1989] estimate and the Musgrave [1989] estimate may be due to the fact that the two calculations cover different time spans.

$\ddagger$ Rintoul and Wunsch [1990] estimate a net loss of nitrate from the $24^{\circ} \mathrm{N}$ to $36^{\circ} \mathrm{N}$ region. The transport across $24^{\circ} \mathrm{N}$ is $\sim 0$ but there is a large northward transport across $36^{\circ} \mathrm{N}$.

model estimates. Riley's [1951] estimates fall into the lower group. We emphasize that with the exception of Riley's estimates (which were obtained from a geostrophic velocity and mixing model) the high OURs are all obtained from the age equation approach, whereas the lower OURs are all based on box models. The only major exceptions to the overall grouping of the results in Figure 3 are the upper two Jenkins [1980] OURs, which are higher than any of the other estimates. We do not give great weight to the reliability of these two OURs, however, since the actual ages used to obtain them are extremely short $(0.42$ and 0.96 years, for the shallower and deeper data points, respectively), and the AOUs are relatively small. Errors that would be considered small at depths with more typical ages of $>5$ years and much higher AOUs would have a major impact on these two shallower data points. They also would be more subject to temporal variability.

We also tend to discount the Riley [1951] results. His geostrophic calculations are based on a very sparse data set. In addition, Rintoul and Wunsch [1990] have shown, with a far more rigorous treatment of the transport in the North Atlantic than that carried out by Riley, that the transport of nutrients is very sensitive to the reference level chosen for geostrophic velocity estimates. The oxygen does not show as much sensitivity because it is rather uniform at depth in the region covered by the Rintoul and Wunsch study, but this is not the case over the larger region covered by Riley's study.

Our discussion will focus on an analysis of the two model approaches that give rise to the high OURs (the age equation approach) and low OURs (the tritium box model approach) in order to determine which value for the remineralization is most appropriate. This will be followed in the conclusion section by a suggestion for a tentative oxygen and nitrogen balance for the subtropical gyre.

We first examine the age equation approach. A possible explanation for the difference in results obtained from the tritium box model and ${ }^{228} \mathrm{Ra}$ age techniques is that the final term on the right-hand side of (8) is not negligible, as has been assumed. If this term is large, then the estimated ages would be too low, and the OURs would be high. Nir [1964], Nir and Lewis [1975], and Lewis and Nir [1978] have discussed some aspects of this problem as it relates to age estimates. A simple one-dimensional model solution of $\mathrm{O}_{2}$ and ${ }^{228} \mathrm{Ra}$ helps illustrate the point and allows us to study the sensitivity of the age estimates to mixing. We will also solve the one-dimensional model for $T$ and ${ }^{3} \mathrm{He}$ so that we can examine the importance of the final term on the right-hand side of (13).

We assume that we are following a trajectory around the gyre that is open to the surface at both ends. The length of the trajectory, $L$, is taken to be $6000 \mathrm{~km}$. Mixing can occur 


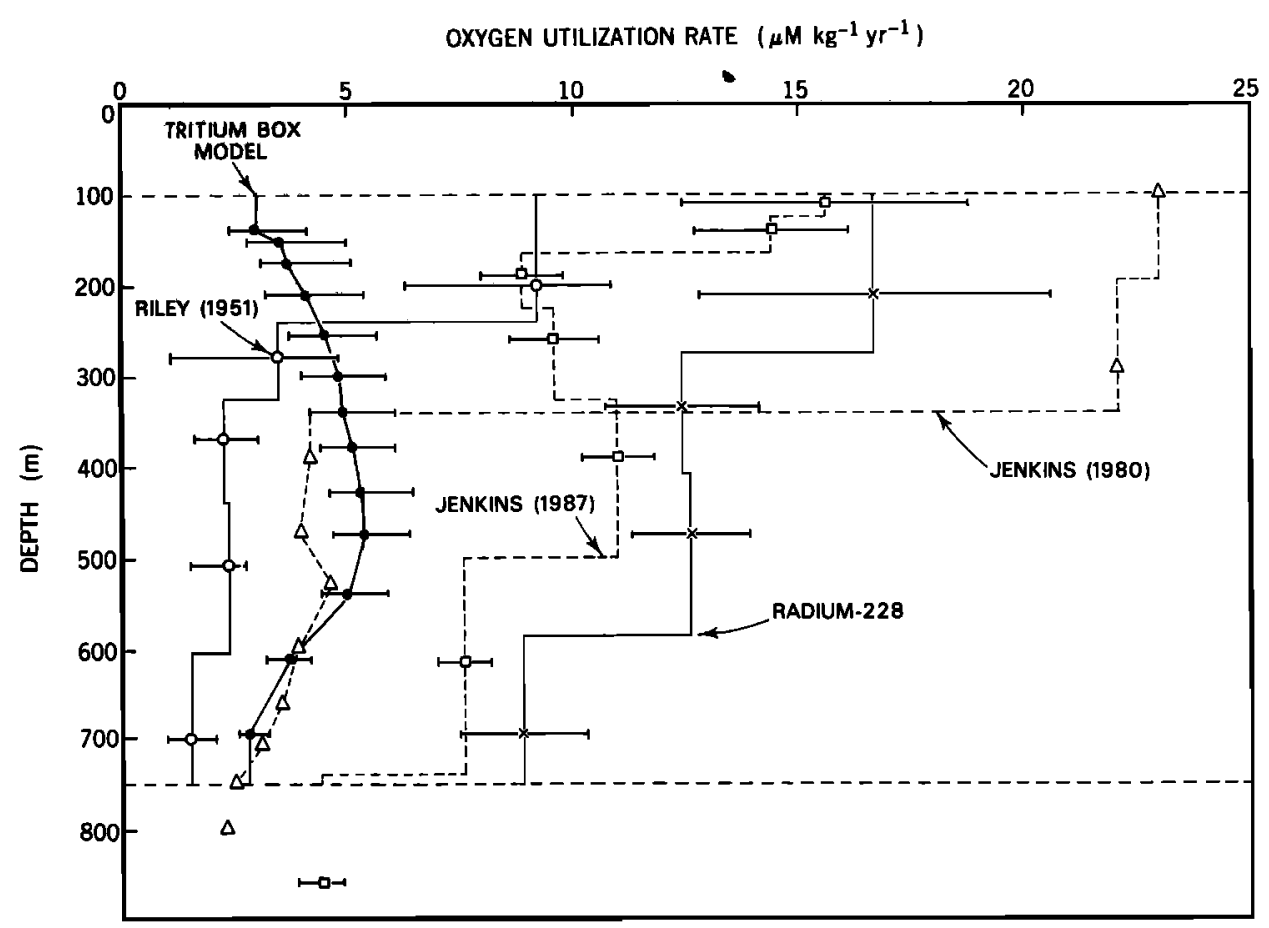

Fig. 3. Apparent oxygen utilization rates from our tritium box model and ${ }^{228} \mathrm{Ra}$ age estimates, from Jenkins' [1980] box model near Bermuda, and from Jenkins' [1987] tritium $/{ }^{3} \mathrm{He}$ age estimates in the Beta Triangle region. Also included for comparison are the OUR estimates of Riley [1951]. The lines show how the integral was performed to find the remineralization rate.

along the trajectory only. A two-dimensional case allowing mixing across trajectories is dealt with by Thiele and Sarmiento [1990]. The equations we solve are

$$
\begin{gathered}
\mathrm{O}=-u \partial \tau_{\mathrm{O}_{2}} / \partial x+\mathrm{K} \partial^{2} \tau_{\mathrm{O}_{2}} / \partial x^{2}+1 \\
\mathrm{O}=-u \partial^{228} \mathrm{Ra} / \partial x+\mathrm{K} \partial^{2}{ }^{228} \mathrm{Ra} / \partial x^{2}-\lambda_{\mathrm{Ra}}{ }^{228} \mathrm{Ra} \\
\partial T / \partial t=-u \partial T / \partial x+\mathrm{K} \partial^{2} T / \partial x^{2}-\lambda_{\mathrm{T}} T \\
\partial^{3} \mathrm{He} / \partial t=-u \partial^{3} \mathrm{He} / \partial x+\mathrm{K} \partial^{2}{ }^{3} \mathrm{He} / \partial x^{2}+\lambda_{\mathrm{T}} T
\end{gathered}
$$

with boundary conditions at $x=0$ and $x=L$ specified as $\tau_{\mathrm{O}_{2}}=0,{ }^{228} \mathrm{Ra}={ }^{228} \mathrm{Ra}_{s}, T=T_{s}$ as given by Dreisigacker and Roether [1978], and ${ }^{3} \mathrm{He}=0$. Equations (14) and (15) have relatively straightforward analytical solutions, but (16) and (17) are solved numerically to more readily include the time variation of the tritium boundary condition. The tracer results are then used to calculate $\tau_{\mathrm{Ra}}$ and $\tau_{\mathrm{THe}}$ from (7) and (12).

In analyzing the model results and their sensitivity to relative magnitudes of advection and mixing, it is convenient to consider the Peclet number, $u x / \mathrm{K}$, where $x$ is a scale length which is here defined from the solution to equation (15):

$$
{ }^{228} \mathrm{Ra}=a e^{x / x+}+b e^{x / x-}
$$

where

$$
x_{ \pm}=\frac{1}{2 \lambda}\left[u \pm\left(u^{2}+4 \lambda \mathrm{K}\right)^{1 / 2}\right]
$$

and $a$ and $b$ are integration constants that are obtained from the boundary conditions. Both $x_{+}$and $x_{-}$are of relevance, one, $x_{+}$, applying to the region where advection enters from the surface carrying tracer with it, and the other, $x_{-}$, applying to the other end of the model where tracer can only enter by diffusing upstream. The corresponding Peclet numbers are

$$
P e_{ \pm}=\frac{u x_{ \pm}}{\mathrm{K}}=\frac{P e_{\lambda}^{2}}{2}\left[1 \pm\left(1+\frac{4}{P e_{\lambda}^{2}}\right)^{1 / 2}\right]
$$

where the radiotracer Peclet number, $P e_{\Lambda}=u /(\lambda K)^{1 / 2}$, is as defined by Jenkins $[1988 a]$.

We therefore see that $P e_{\lambda}$ is the critical term. When $P e_{\lambda}$ $\ll 1$, that is to say when $\lambda \mathrm{K} \gg u$, then $P e_{+} \sim \pm P e_{\lambda}$. Figure 4 shows the ratio $\tau_{\mathrm{Ra}} / \tau_{\mathrm{O}}$, for the extreme case where $u=0$ for various values of $\mathrm{K}$. It should be noted that the $\tau_{\mathrm{O}_{2}}$ includes mixing in it (cf. equation (4)), so that the comparison in Figure 4 is quite different than the comparison of the

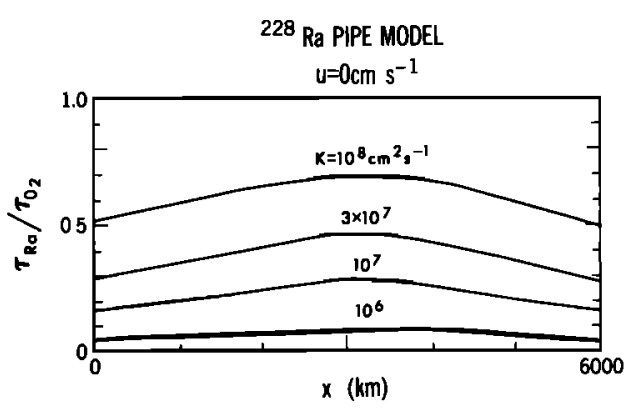

Fig. 4. Solution of one-dimensional pipe model with diffusion only $(u=0)$. Note that the ratio $\tau_{\mathrm{Ra}} / \tau_{\mathrm{O}_{2}}$ gets closer to 1 with increasing mixing. 


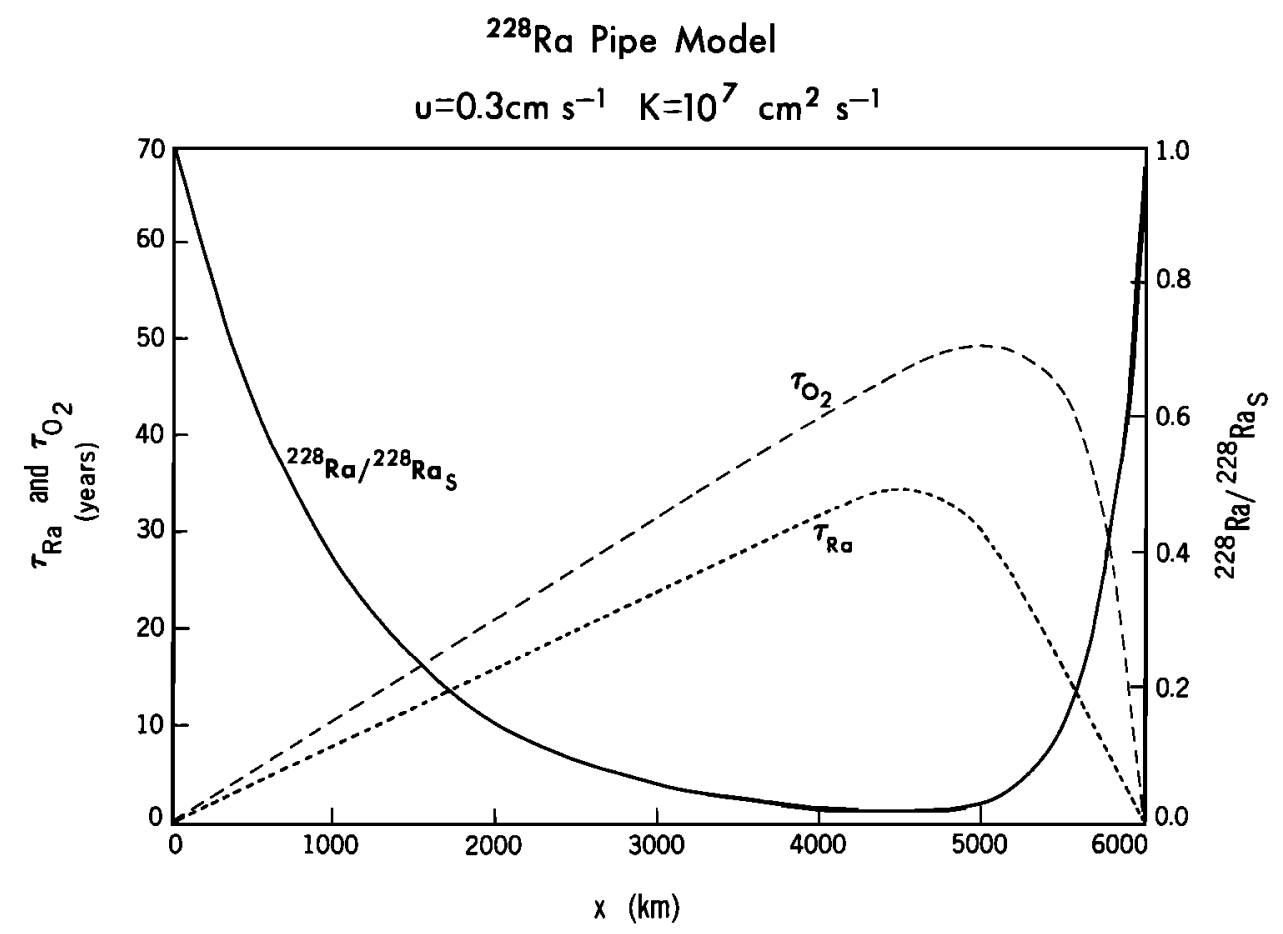

Fig. 5. Normalized radium concentration, $\tau_{\mathrm{O}_{2}}$ and $\tau_{\mathrm{Ra}}$ for the case $u=0.3 \mathrm{~cm} \mathrm{~s}^{-1}$ and $\mathrm{K}=10^{7} \mathrm{~cm} \mathrm{~s}^{-1}$. Advection is to the right.

$\tau_{\text {THe }}$ with the "box-car" advection only time scale of Jenkins [1988a]. One sees that when mixing is dominant the ratio is directly related to $\mathrm{K}$, with small $\mathrm{K}$ leading to small $\tau_{\mathrm{Ra}} / \tau_{\mathrm{O}_{2}}$, and vice-versa.

At the other extreme, when $P e_{\lambda} \gg 1,(20)$ defines two regions, one, $0>P e_{-}>-1$, where diffusion is dominant, and the other, $P e_{+} \rightarrow \infty$, where advection is dominant. Figure 5 shows a solution for ${ }^{228} \mathrm{Ra}$ in an intermediate range, where $u=0.3 \mathrm{~cm} \mathrm{~s}^{-1}$ and $\mathrm{K}=10^{7} \mathrm{~cm}^{2} \mathrm{~s}^{-1}$, giving $P e_{-}=$ -0.76 and $P e_{+}=3.1$ with corresponding scale lengths $x_{-}=$ $-252 \mathrm{~km}$ and $x_{+}=1040 \mathrm{~km}$, respectively; $u$ is positive to the right in this diagram. The ${ }^{228} \mathrm{Ra}$ reflects the pattern of advection distinctly, with much greater penetration where the water flows in from the surface. The model results shown in Figure 5 have ${ }^{228} \mathrm{Ra}$ ages as high as 35 years. In fact, with the present detection limit for radium 228 of the order of 0.1 dpm (disintegrations per minute) per $100 \mathrm{~kg}$ and with ${ }^{228} \mathrm{Ra}_{s} \sim 2 \mathrm{dpm} / 100 \mathrm{~kg}$ (Table 2), the maximum resolution of $\tau_{\mathrm{Ra}}$ is approximately 25 years. This is comparable to the time since the maximum entry of tritium into the oceans in 1963, which sets an upper limit for the resolution of $\boldsymbol{\tau}_{\mathrm{THe}}$.

Figure 6 shows the sensitivity of $\tau_{\mathrm{Ra}^{2}} / \tau_{\mathrm{O}_{2}}$ to mixing for $u=$ $0.3 \mathrm{~cm} \mathrm{~s}^{-1}$ and $1.0 \mathrm{~cm} \mathrm{~s}^{-1}$ and various values of $\mathrm{K}$. The corresponding scale lengths and Peclet numbers are summarized in Table 4 . We see that in the advectively dominated $\mathrm{Pe}_{+}$region to the left of the diagram, changes in mixing have the opposite effect from the pure diffusion case shown in Figure 4. Increased mixing makes $\tau_{\mathrm{Ra}} / \tau_{\mathrm{O}_{2}}$ smaller, rather than larger. The diffusively dominated $\mathrm{Pe}_{-}$region to the right of the diagram has the same sensitivity to mixing as the pure diffusion case only for the cases with very small $u$ and large K (see upper panel of Figure 6).

Figures 7 and 8 for the tritium- ${ }^{3} \mathrm{He}$ simulations exhibit the same basic behavior as the ${ }^{228} \mathrm{Ra}$ simulations. The kinks in the tritium- ${ }^{3} \mathrm{He}$-based curves are due to the time history of the tracer input and not to any numerical problems. The $\tau_{\mathrm{THe}}$ age given is for the tritium and ${ }^{3} \mathrm{He}$ distribution predicted in 1977. The peak tritium input occurred in 1963, which means that with 1977 data the tritium- ${ }^{3} \mathrm{He}$ clock is not very effective for dating waters $>14$ years. Much of the $\tau_{\mathrm{THe}}$ deviation from $\tau_{\mathrm{O}_{2}}$ is due to this. Note that the $\tau_{\mathrm{THe}} / \tau_{\mathrm{O}_{2}}$ is somewhat greater than 1 in certain parameter ranges whereas $\tau_{\mathrm{Ra}} / \tau_{\mathrm{O}_{2}}$ can never be greater than 1 .

What can we conclude from the experiments illustrated in Figures 4-8? The conclusion of greatest relevance to the present study is that it would take relatively extreme parameter ranges to compromise the calculations of OUR from $\tau_{\mathrm{Ra}}$ and $\tau_{\mathrm{THe}}$ by the factor of $\sim 2$ to 3 that would be needed to reduce the age-based OUR estimates so that they agreed with the box model estimates. Jenkins [1987] gives horizontal diffusivity and velocity estimates in the Beta Triangle region of order $5 \times 10^{6} \mathrm{~cm}^{2} \mathrm{~s}^{-1}$ and $0.5 \mathrm{~cm} \mathrm{~s}^{-1}$, respectively. The velocity estimates are, of course, higher at shallower depths and lower at greater depths. The value chosen is approximately representative of the $\sigma_{\theta}=27.1$ surface. Figures 6 and 8 show that it takes horizontal diffusivities as high as $3 \times 10^{7} \mathrm{~cm}^{2} \mathrm{~s}^{-1}$ and velocities as low as $0.3 \mathrm{~cm} \mathrm{~s}-1$ to reduce the OUR estimates by a factor of approximately 2 . Furthermore, $\tau_{\mathrm{THe}}$ is more sensitive than $\tau_{\mathrm{Ra}}$, whereas we would want the reverse to be the case. The effect of mixing on the tritium $/{ }^{3} \mathrm{He}$-based estimates has been investigated very carefully by Jenkins [1987] in the Beta Triangle region. He concludes from his study that the mixing has a negligible impact on his estimates. We have no reason, based on the above or on the two-dimensional study of Thiele and Sarmiento [1990], to disagree with his arguments.

We examine the box modeling approach next. Doney and Jenkins [1989] have recently investigated the effect of the 
${ }^{228} \mathrm{Ra}$ PIPE MODEL
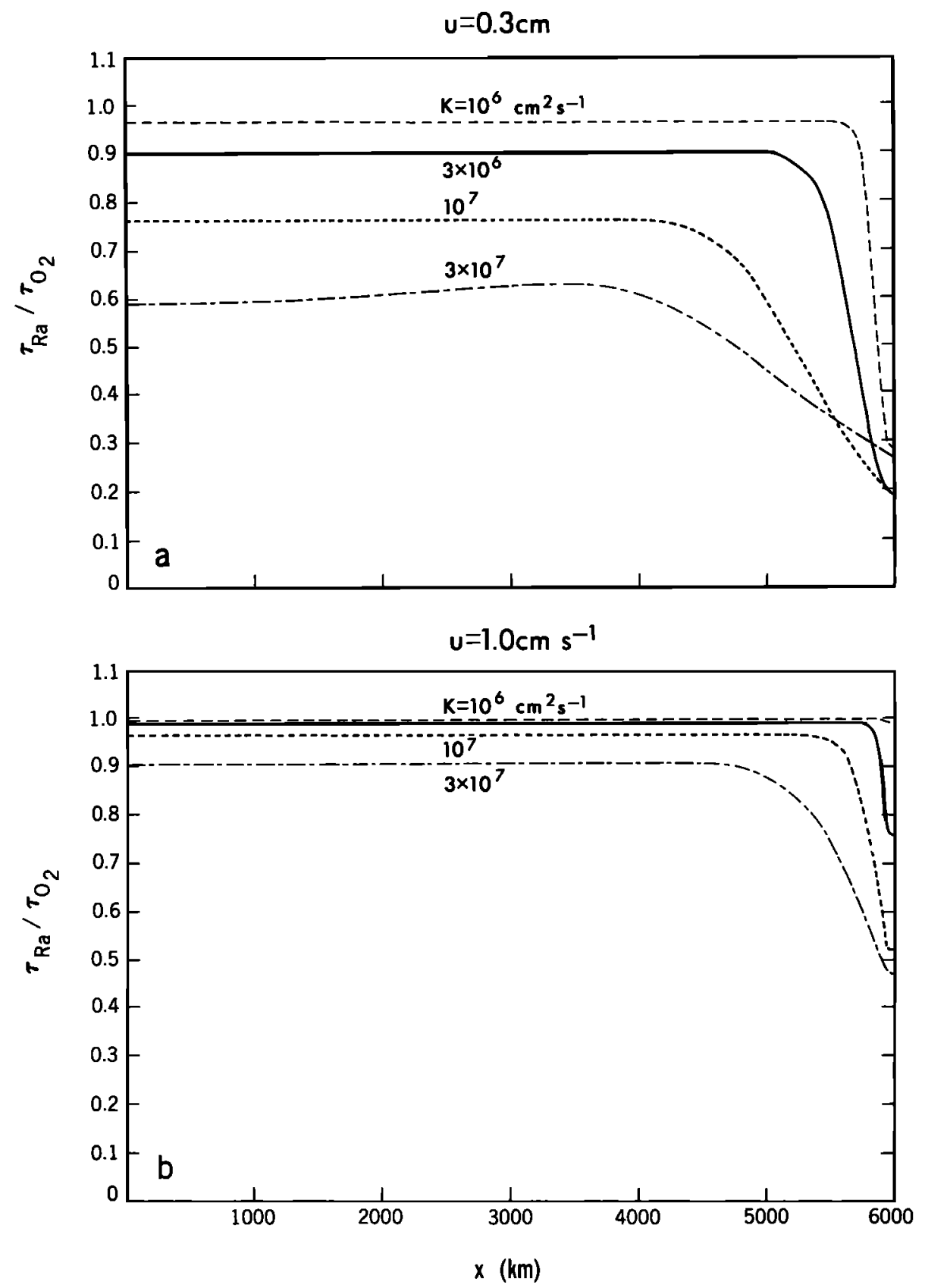

Fig. 6. The ratio $\tau_{\mathrm{Ra}} / \tau_{\mathrm{O}_{2}}$ for the pipe model for various values of mixing and $(a) u=0.3 \mathrm{~cm} \mathrm{~s}{ }^{-1}$ and $(b) u=1.0 \mathrm{~cm}$ $\mathrm{s}^{-1}$. Note that here, unlike Figure 4 , the age ratio gets smaller with increasing mixing, except in the region to the right of the diagram with $u=0.3 \mathrm{~cm} \mathrm{~s}^{-1}$, where entry of tracer is diffusively dominated and the sensitivity to $\mathrm{K}$ is as in Figure 4.

boundary condition, $T_{s}$ in (1), on tracer estimates of thermocline ventilation rates, with particular application to estimates based on tritium inventories as compared with those that are based on helium 3. The salient result is that unless one uses wintertime surface tritium concentrations to drive the ocean model, tritium-based ventilation rate estimates will be too low, particularly near the surface. This study serves nicely to explain the rather peculiar result, from the tritium inventory calculations, of the OUR being approximately constant above $\sigma_{\theta} \sim 27.2$ (see Figure 3), when in fact one would expect it to increase at shallow depths. The shallower layers are more sensitive to the inclusion of wintertime dilution than are the deep layers, so the Doney and Jenkins approach gives shorter ventilation time scales (which would result in higher OUR rates) on the shallower surfaces than Sarmiento [1983] obtained.

There is little wintertime tritium data to test the extent to which the Doney and Jenkins' hypothesis is correct. There are strontium 90 data, however. Figure 9 shows the Dreisgacker and Roether [1978] strontium 90 surface concentra- 
TABLE 4. Scale Lengths and Peclet Numbers for Values of $u$ and $K$ Used in Figures 6 and 8

\begin{tabular}{ccrrrr}
\hline $\begin{array}{c}u, \\
\mathrm{~cm} \mathrm{~s}^{-1}\end{array}$ & $\begin{array}{c}\mathrm{K}, \\
\mathrm{cm}^{2} \mathrm{~s}^{-1}\end{array}$ & $\begin{array}{c}x_{+}, \\
\mathrm{km}\end{array}$ & $\begin{array}{c}x_{-}, \\
\mathrm{km}\end{array}$ & $P e_{+}$ & $P e_{-}$ \\
\hline 0.3 & $10^{6}$ & 820 & -32 & 24.5 & -0.96 \\
0.3 & $3 \times 10^{6}$ & 875 & -90 & 8.8 & -0.90 \\
0.3 & $10^{7}$ & 1040 & -252 & 3.1 & -0.76 \\
0.3 & $3 \times 10^{7}$ & 1360 & -577 & 1.4 & -0.58 \\
1.0 & $10^{6}$ & 2630 & -10 & 263.0 & -1.00 \\
1.0 & $3 \times 10^{6}$ & 2650 & -30 & 88.2 & -0.99 \\
1.0 & $10^{7}$ & 2710 & -96 & 27.1 & -0.96 \\
1.0 & $3 \times 10^{7}$ & 2890 & -272 & 9.6 & -0.91 \\
\hline
\end{tabular}

tion obtained with the same model as the tritium concentration boundary condition that Sarmiento [1983] used. Also shown on the same figure are winter to summer extremes obtained by averaging unpublished data from eight weathership stations (A, B, C, D, E, I, J, and K) that were obtained by V. Bowen's laboratory at Woods Hole Oceanographic Institution, Woods Hole, Massachusetts, during various portions of the period 1962-1974. The data at all eight weathership stations were normalized to weathership station $\mathrm{C}$ at $52^{\circ} 15^{\prime} \mathrm{N} 35^{\circ} 39^{\prime} \mathrm{W}$ before averaging. Table 5 shows the normalization factors that were used, which were obtained by averaging the ratio of all combined "summer" (August, September, October) and "winter" (February, March, April) averages to weathership $C$ averages. The months chosen to represent summer and winter are those generally showing the maximum seasonal excursion. Station $C$ was chosen as the reference station because it has the most complete set of data. The increasing trend towards the south is a result of the strontium 90 fallout pattern [cf. Sarmiento and Gwinn, 1986]. The Dreisigacker and Roether concentra- tions are in all cases greater than the wintertime concentrations at the weathership stations. Note, however, that the extent of the difference depends on which station is chosen for reference. If the average ratio of 1.06 had been used, or if weatherships $D, E$, or $K$, more centrally located in the subtropical gyre, had been used, the difference between the Dreisigacker and Roether function and the winter observations would be smaller.

It remains to be seen if the differences between the wintertime strontium 90 concentrations and the Dreisigacker and Roether [1978] function that do exist are sufficient, when translated into the equivalent effect in tritium, to give an effect as large as Doney and Jenkins found in their work. If they are, a very rough estimate of OURs from the ventilation ages obtained by Doney and Jenkins [1989] and average AOUs estimated from the figures in Jenkins [1987] suggests that vertically integrated remineralization estimates based on tritium may be as much as a factor of 1.5 to 2.0 lower than those based on helium 3 , which is relatively insensitive to the aforementioned effect since it has such a rapid atmosphereocean equilibration time.

The other major uncertainty regarding the tritium box model is the assumption that the tritium and AOU concentrations in the outflow from the interior box, $T_{I}$, and $\mathrm{AOU}_{I}$, can be represented by the average tritium and AOU concentrations in the box (see Sarmiento [1983] for a discussion of this point). If the appropriate value for $T_{I}$ is in fact higher than the average, then $\tau_{\text {box }}$ would be overestimated and OUR underestimated by using the average. Similarly, if $\mathrm{AOU}_{I}$ is in fact higher than the average, the OUR would be underestimated by using the average. Without direct measurements of the correlation between tracer concentrations and velocities at the outcrop of the interior box, we have no way of knowing for certain what values for $T_{I}$ and $\mathrm{AOU}_{I}$ are appropriate. In view of the fact that the ${ }^{228} \mathrm{Ra}$ and tritium/

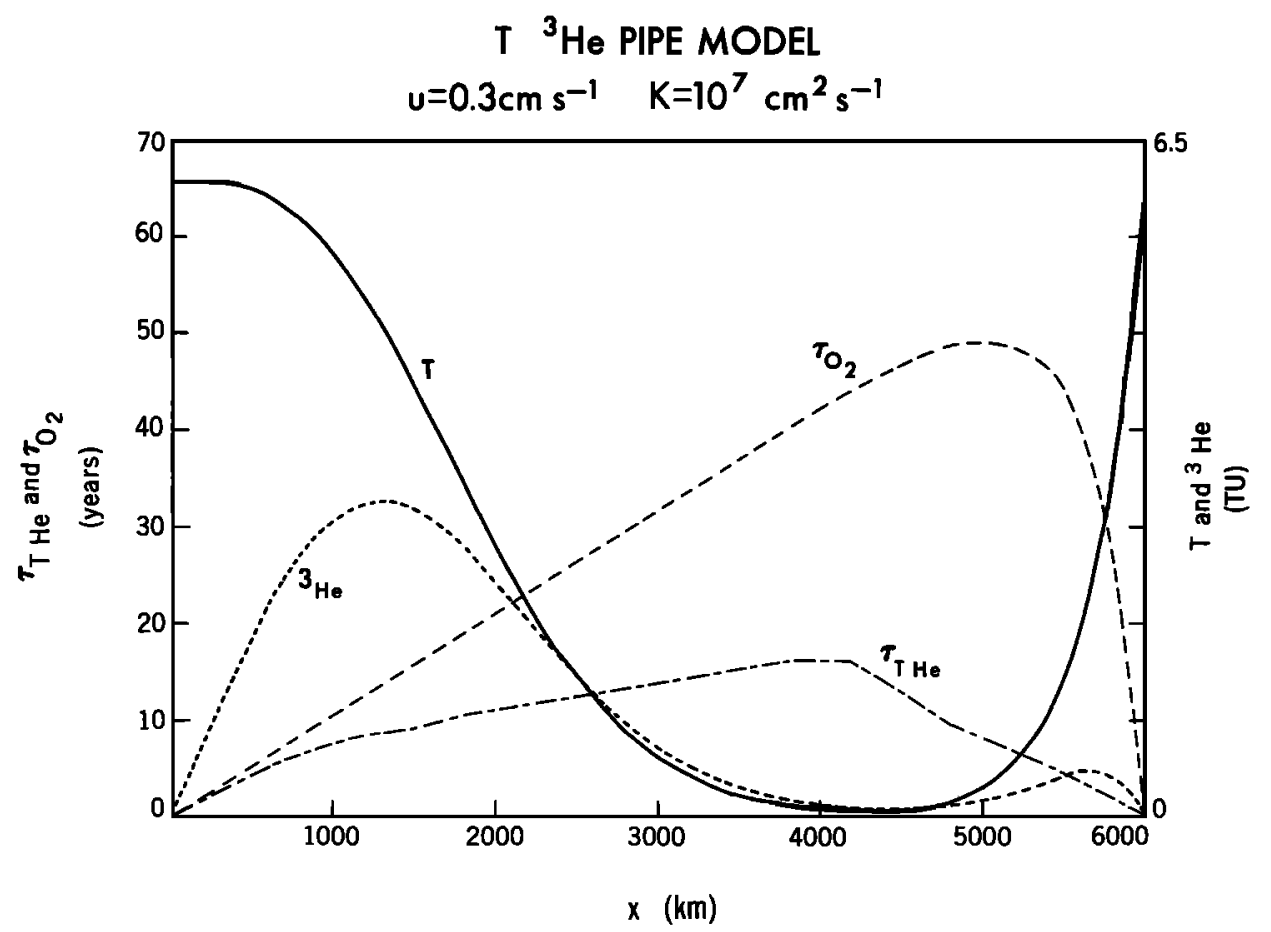

Fig. 7. Tritium and ${ }^{3} \mathrm{He}$ concentrations, and $\tau_{\mathrm{O}_{2}}$ and $\tau_{\mathrm{THe}}$ for $u=0.3 \mathrm{~cm} \mathrm{~s}^{-1}$ and $\mathrm{K}=10^{7} \mathrm{~cm}^{2} \mathrm{~s}^{-1}$. 


\section{T ${ }^{3} \mathrm{He}$ PIPE MODEL}
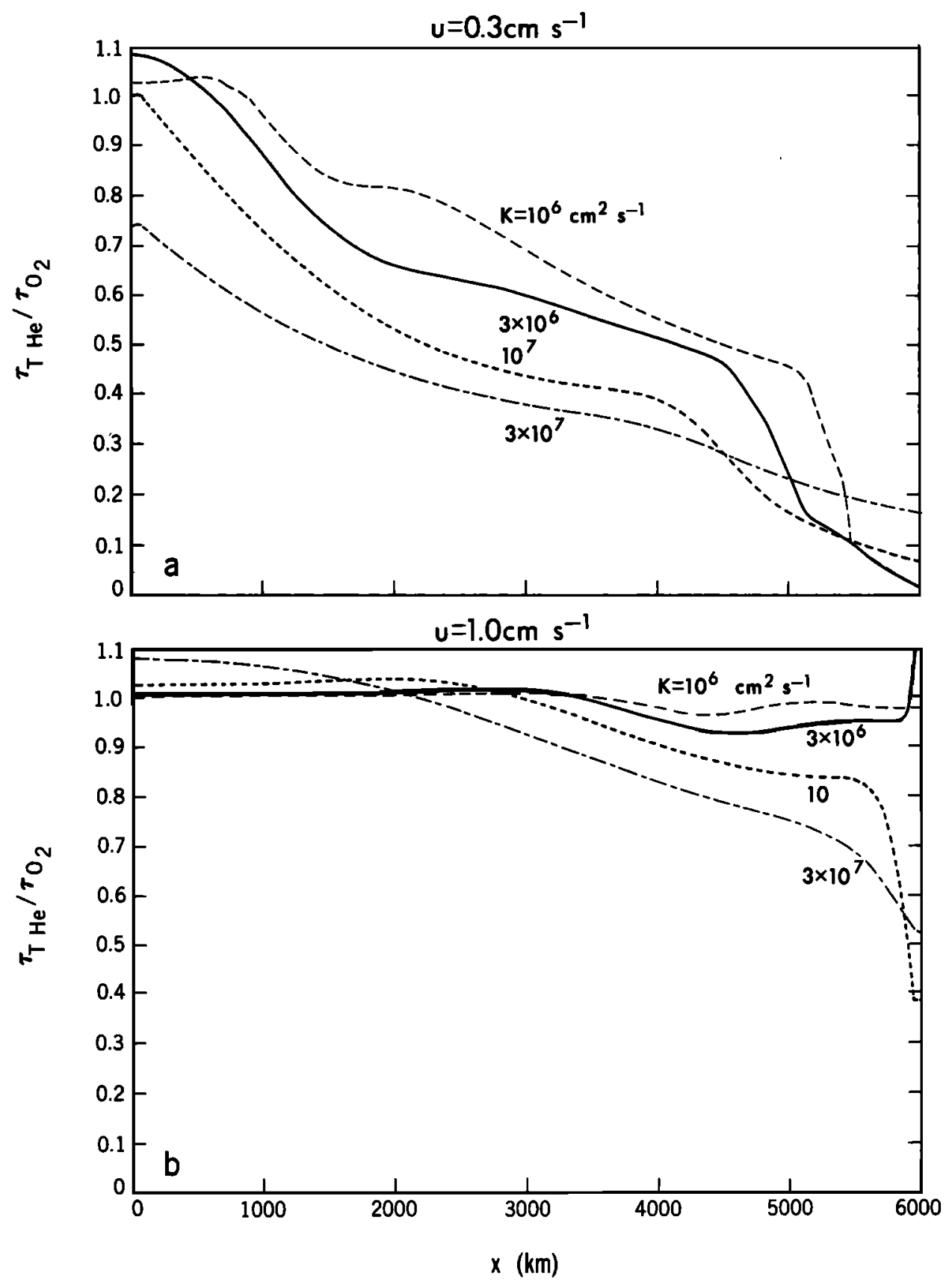

Fig. 8. The ratio $\tau_{\mathrm{THe}} / \tau_{\mathrm{O}_{2}}$ as described for $\tau_{\mathrm{Ra}} / \tau_{\mathrm{O}_{2}}$ in Figure 6 for $(a) u=0.3 \mathrm{~cm} \mathrm{~s}^{-1},(b) u=1.0 \mathrm{~cm} \mathrm{~s}^{-1}$.

helium 3 age approaches appear to be reasonably solid, we strongly suspect that the problem lies in some combination of our assumption regarding the value of $\mathrm{AOU}_{I}$ and/or $T_{I}$ and some of the issues raised by the Doney and Jenkins [1989] study.

An additional possible explanation for the differences in the OUR estimates shown in Figure 3 is that they are due to spatial or temporal variability. It will be difficult to say anything very solid about these topics until more observations are obtained. One of the attractive aspects of the various techniques used in obtaining the OUR estimates is that they average out short-term temporal variability. Tem- poral variability on a time scale of a year or even a few years is therefore not likely to be an important factor in the OUR estimates. For example, in the Beta Triangle region, Jenkins [1987] finds OUR by taking the slope of AOU versus tritium $/{ }^{3} \mathrm{He}$ age. The age ranges, and therefore the time over which one is in a sense averaging, are greater than 1 year on the shallowest surfaces and in excess of a decade on deeper surfaces. The calculations in the Sargasso Sea location [Jenkins, 1980] have somewhat shorter but not dissimilar time scales except in the shallowest two data points. The other techniques used to obtain the OURs in Figure 3, those presented here, and that of Riley [1951], are large-scale 


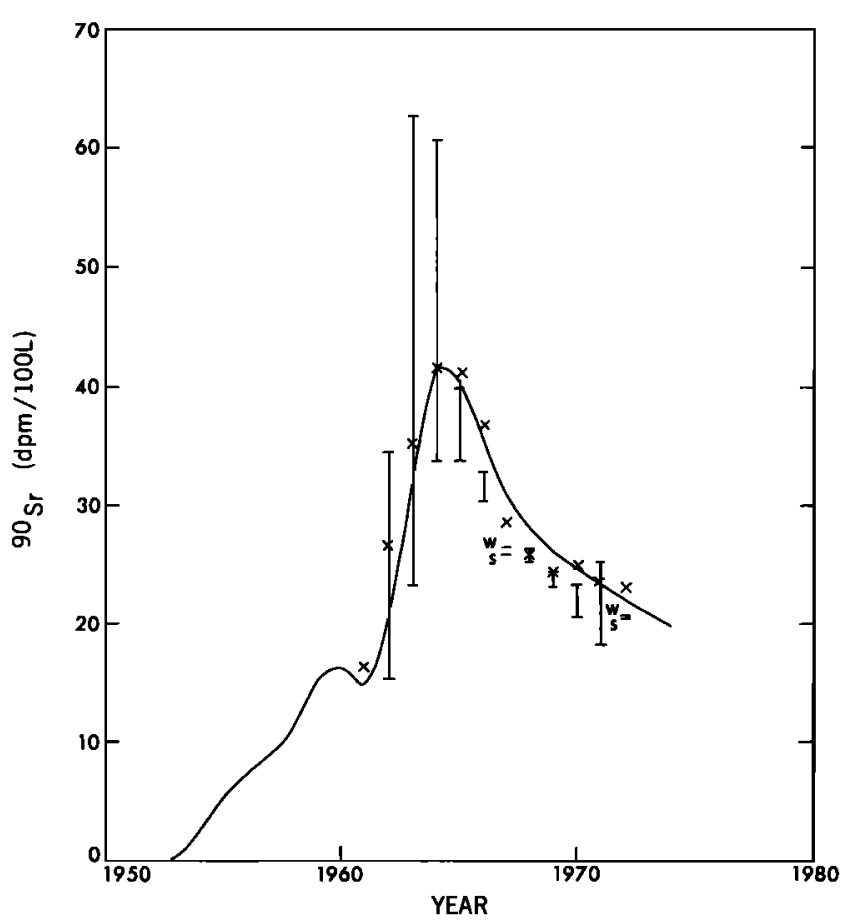

Fig. 9. Strontium 90 surface concentrations estimated from observations by Dreisigacker and Roether [1978] (crosses); estimated by a model Dreisigacker and Roether [1978] (solid line); and estimated by us from unpublished weathership data from V. Bowen's laboratory at Woods Hole Oceanographic Institution. Table 5 shows the location of the stations. The weathership averages are indicated by bars, with the top being nominal summertime concentrations (August, September, October) and the lower being nominal wintertime concentrations (February, March, April). In 1967 and 1972 the wintertime concentrations were slightly higher than the summertime concentrations.

spatial averages (see Table 3) and thus, in effect, also temporal averages over many years.

What about spatial variability? The Beta Triangle region [Jenkins, 1987] has higher OURs than the region near Bermuda [Jenkins, 1980] except for the top two data points at the latter site, which anyway appear to be anomalous. Is the Beta Triangle region more productive? It is difficult to tell with the type of data presently available [e.g., KoblentzMishke et al., 1970]. The region from which data were obtained for Riley's [1951] OUR estimates differs from that used in our tritium inventory and ${ }^{228} \mathrm{Ra}$ estimates. Resolving the role of spatial variability will be difficult until the full TTO data set becomes available for tritium and helium 3 so

TABLE 5. Average Normalization Factors for Seasonal ${ }^{90} \mathrm{Sr}$ Data Relative to Weathership Station C

\begin{tabular}{ccc}
\hline Station & Position & Normalization \\
\hline $\mathrm{A}$ & $62^{\circ} 00^{\prime} \mathrm{N} 35^{\circ} 00^{\prime} \mathrm{W}$ & 0.88 \\
$\mathrm{~B}$ & $56^{\circ} 30^{\prime} \mathrm{N} 51^{\circ} 00^{\prime} \mathrm{W}$ & 0.93 \\
$\mathrm{C}$ & $52^{\circ} 15^{\prime} \mathrm{N} 35^{\circ} 30^{\prime} \mathrm{W}$ & 1.00 \\
$\mathrm{D}$ & $44^{\circ} 00^{\prime} \mathrm{N} 41^{\circ} 00^{\prime} \mathrm{W}$ & 1.19 \\
$\mathrm{E}$ & $35^{\circ} 00^{\prime} \mathrm{N} 48^{\circ} 00^{\prime} \mathrm{W}$ & 1.23 \\
$\mathrm{I}$ & $59^{\circ} 00^{\prime} \mathrm{N} 19^{\circ} 00^{\prime} \mathrm{W}$ & 0.98 \\
$\mathrm{~J}$ & $52^{\circ} 30^{\prime} \mathrm{N} 20^{\circ} 00^{\prime} \mathrm{W}$ & 1.03 \\
$\mathrm{~K}$ & $45^{\circ} 00^{\prime} \mathrm{N} 16^{\circ} 00^{\prime} \mathrm{W}$ & 1.21 \\
& & 1.06 \\
\hline
\end{tabular}

the various techniques can be compared directly at the same location.

\section{Conclusion}

Given the foregoing, we conclude that the tracer age equation based estimates are more reliable than the tritium box model estimates. In putting together an oxygen balance for the subtropical gyre as a whole we choose the ${ }^{228} \mathbf{R a}$ estimate of $8.5 \pm 0.8 \mathrm{~mol} \mathrm{~m}^{-2} \mathrm{yr}^{-1}$ as most representative since it is based on measurements from the entire region. This number may actually be an underestimate, in that it covers only the 100 - to $750-\mathrm{m}$ depth range. On the other hand, mixing would tend to make the estimate too large (by at most a few tens of percent), judging from Figure 6.

Unfortunately, we have no equivalent gyre-scale estimate of the new production at the surface. The estimates of Musgrave et al. [1988] and Spitzer and Jenkins [1989], which give an average $\mathrm{O}_{2}$ production of $\sim 4.6 \pm 1.6 \mathrm{~mol} \mathrm{~m}^{-2} \mathrm{yr}^{-1}$, are from the time series station near Bermuda, which may or may not be representative of the subtropical gyre as a whole. This estimate of new production is lower by $3.9 \pm 1.9 \mathrm{~mol}$ $\mathrm{m}^{-2} \mathrm{yr}^{-1}$ than our estimate of the remineralization.

Until recently, we would have felt obliged to conclude that this inconsistency between new production and remineralization rates represented a problem with the models used to obtain these estimates or a problem with spatial coverage. The recent work of Rintoul and Wunsch [1990] on the nitrate balance in the $24^{\circ} \mathrm{N}$ to $36^{\circ} \mathrm{N}$ region, which shows a net export of nitrate across $36^{\circ} \mathrm{N}$ which they believe to be balanced by an import of dissolved organic matter, and the recent work of Sugimura and Suzuki [1988] and Suzuki et al. [1985], which show that the dissolved organic carbon content in the oceans is much larger than had previously been thought, suggest the possibility of a different interpretation. It is still not possible to eliminate spatial coverage as a problem, but the above numbers are entirely consistent with the import of organic matter that is required by Rintoul and Wunsch. We therefore propose these numbers as a tentative budget for oxygen in the subtropical gyre, subject to future confirmation with more appropriate spatial coverage.

We obtain an estimate for nitrogen remineralization by dividing our oxygen remineralization of $8.5 \pm 0.9 \mathrm{~mol} \mathrm{~m}^{-2}$ $\mathrm{yr}^{-1}$ by $9.1 \pm 0.4$, which is the $-\mathrm{O}_{2}: \mathrm{N}$ remineralization ratio estimated from GEOSECS and TTO data by Minster and Boulahdid [1987]. This gives a nitrogen remineralization rate of $\sim 0.93 \pm 0.11 \mathrm{~mol} \mathrm{~m}^{-2} \mathrm{yr}^{-1}$. Rintoul and Wunsch [1990] obtain a net export of nitrate from the $24^{\circ} \mathrm{N}$ to $36^{\circ} \mathrm{N}$ region which is equivalent to an average loss rate of $0.51 \pm$ $0.21 \mathrm{~mol} \mathrm{~m}^{-2} \mathrm{yr}^{-1}$. The difference between the total remineralization and lateral export gives an export of nitrate into the mixed layer, i.e., a new production, of $0.42 \pm 0.24 \mathrm{~mol}$ $\mathrm{m}^{-2} \mathrm{yr}^{-1}$. This is consistent with the nitrogen new production estimate of $0.6 \pm 0.2 \mathrm{~mol} \mathrm{~m}^{-2} \mathrm{yr}^{-1}$ that Jenkins [1988b] obtained for the site near Bermuda and with the $100-\mathrm{m}$ particle flux of $0.33 \mathrm{~mol} \mathrm{~m} \mathrm{mr}^{-1}$ that Altabet [1989] obtained, also near Bermuda. The new production $-\mathrm{O}_{2}: \mathrm{N}$ ratio of $11.0 \pm 7.1$ which we obtain is also consistent with the particulate $-\mathrm{O}_{2}: \mathrm{N}$ ratios of 10.2 to 13.4 obtained by Martin et al. [1987] for the upper $1000 \mathrm{~m}$ from sediment trap observations. This agreement is probably fortuitous, given the large errors involved. Note that the foregoing balances require that the laterally imported organic matter which is 
regenerated in the thermocline must have a rather low $-\mathrm{O}_{2}: \mathrm{N}$ ratio of $7.6 \pm 4.8$.

We again run into the problem that the spatial coverage of the ${ }^{228} \mathrm{Ra}$ data set is not equivalent to the region studied by Rintoul and Wunsch [1990]. We tried using a subset of our ${ }^{228} \mathrm{Ra}$ data to obtain an oxygen utilization rate in the $24^{\circ} \mathrm{N}$ to $36^{\circ} \mathrm{N}$ region. The value we obtained, $13.6 \pm 1.7 \mathrm{~mol} \mathrm{~m}^{-2}$ $\mathrm{yr}^{-1}$, is equivalent to a nitrogen remineralization of $1.5 \pm 0.2$ mol $\mathrm{m}^{-2} \mathrm{yr}^{-1}$. However, we distrust this estimate since it leaves out many of the data points at the more extreme ranges of age and AOU which help to define the curves shown in Figure 2.

The major overall point we wish to emphasize with the above considerations is that we need to be open to the possibility first suggested by Rintoul and Wunsch [1990] that the oxygen and nitrogen remineralization rates may be greater (or smaller) than the new production, with the balance being made up by an import (or export) of dissolved organic matter. The measurements of Sugimura and Suzuki [1988] and Suzuki et al. [1985] in the Pacific Ocean are consistent with this, in that they show substantial gradients of dissolved organic carbon and nitrogen throughout the water column.

We also wish to emphasize the value of being able to put together budgets for oxygen as well as nitrogen. These two tracers, phosphate also being of use, respond to different processes and thus provide complementary information. Nitrogen can be transported in organic as well as inorganic form. Thus the case for transport of dissolved organic matter made by Rintoul and Wunsch [1990] would have been difficult to make with oxygen observations alone. Another example in the mixed layer is that nitrate is supplied primarily by transport from below, whereas oxygen can be gained or lost by gas exchange at the air-sea interface. Requiring mixed layer models such as that of Musgrave et al. [1988] to obtain an internal consistency between the oxygen and nitrogen new production estimates would be a powerful constraint on the models.

A final point concerns the relationship of the oxygen utilization rate to thermocline ventilation. The tritium box model, which gives a low oxygen utilization rate of 2.4 to 3.5 mol m ${ }^{-2} \mathrm{yr}^{-1}$, compared with a ${ }^{228} \mathrm{Ra}$-based estimate of $8.5 \pm 0.8 \mathrm{~mol} \mathrm{~m}^{-2} \mathrm{yr}^{-1}$, also gives a thermocline ventilation rate of $40 \times 10^{6} \mathrm{~m}^{3} \mathrm{~s}^{-1}$. This ventilation rate is consistent with the recent modeling study of Huang [1990]. Could the thermocline ventilation in fact be several times larger, as implied by the difference between the above oxygen utilization rate results? The box model study of Doney and Jenkins [1989] supports such a picture of greater thermocline ventilation, but we are convinced that a final answer to this issue is going to require us to address even more precisely than Doney and Jenkins the nature of exchange between the surface mixed layer and the thermocline in such box models. The flux of oxygen from the surface mixed layer into the interior can vary greatly for a given physical exchange rate depending on what the concentration gradient at the interface is. This concentration gradient may be significantly underrepresented by using the average interior AOU concentration for $\mathrm{AOU}_{I}$ in (2). We will address this topic in a future study.

Acknowledgments. Discussions with J. R. Toggweiler and the assistance of Johann Callan and Phil Tunison in the preparation of this manuscript are gratefully acknowledged. A review by Scott Doney helped greatly to improve the manuscript. Richard Rotter and Rochelle Slater contributed to the measurement of radium 228. The research of J.L.S. and R.M.K. was supported by NSF grants OCE-8215261, OCE-85-17014, and OCE-86-13326. G.T. was supported by a postdoctoral stipend from the German Research Society, and W.S.M. was supported by NSF grant OCE-8216611.

\section{REFERENCES}

Altabet, M. A., Particulate new nitrogen fluxes in the Sargasso Sea, J. Geophys. Res., 94, 12,771-12,780, 1989.

Brewer, P. G., J. L. Sarmiento, and W. M. Smethie, The Transient Tracers in the Oceans (TTO) program: The North Atlantic study, 1981; The Tropical Atlantic study, 1983, J. Geophys. Res., 90, 6903-6906, 1985

Doney, S. C., and W. J. Jenkins, The effect of boundary conditions on tracer estimates of thermocline ventilation rates, J. Mar. Res., 46, 947-965, 1989.

Dreisigacker, E., and W. Roether, Tritium and Sr-90 in North Atlantic surface water, Earth Planet. Sci. Lett., 38, 301-312, 1978.

Emerson, S., Seasonal oxygen cycles and biological new production in surface waters of the Subarctic Pacific Ocean, J. Geophys. Res., 92, 6535-6544, 1987.

Eppley, R. W., New production: History, methods, problems, in Productivity of the Ocean: Present and Past, edited by W. H. Berger, U. S. Smetacek, and G. Wefer, pp. 85-97, John Wiley, New York, 1989.

Huang, R.-X., On the three-dimensional structure of the wind driven circulation in the North Atlantic, Dyn. Atmos. Oceans, in press, 1990.

Jenkins, W. J., Tritium-helium dating in the Sargasso Sea: A measurement of oxygen utilization rates, Nature, 196, 291-292, 1977.

Jenkins, W. J., Tritium and ${ }^{3} \mathrm{He}$ in the Sargasso Sea, J. Mar. Res., $38,533-569,1980$.

Jenkins, W. J., Oxygen utilization rates in the North Atlantic subtropical gyre and primary production in oligotrophic systems, Nature, 300, 246-248, $1982 a$.

Jenkins, W. J., ${ }^{3} \mathrm{H}$ and ${ }^{3} \mathrm{He}$ in the Beta Triangle: Observations of gyre ventilation and oxygen utilization rates, J. Phys. Oceanogr., 17, 763-783, 1987.

Jenkins, W. J., The use of anthropogenic tritium and helium-3 to study subtropical gyre ventilation and circulation, Philos. Trans. R. Soc. London, Ser. A, 325, 43-61, $1988 a$.

Jenkins, W. J., Nitrate flux into the euphotic zone near Bermuda, Nature, 331, 521-523, $1988 b$.

Jenkins, W. J., and J. C. Goldman, Seasonal oxygen cycling and primary production in the Sargasso Sea, J. Mar. Res., 43, 465-491, 1985.

Key, R. M., J. L. Sarmiento, and W. S. Moore, Preliminary data report, Distribution of Ra-228 and Ra-226 in the Atlantic Ocean, Tech. Rep. 85-1, TTO Test Cruise, TTO NAS Legs 1-3, November, 1985.

Knox, F., and M. McElroy, Changes in atmospheric $\mathrm{CO}_{2}$ : Influence of marine biota at high latitudes, J. Geophys. Res., 89, 4629-4637, 1984.

Koblentz-Mishke, O. J., V. V. Volkovinsky, and J. G. Kabanova, Plankton primary production of the world ocean, in Scientific Exploration of the South Pacific, edited by W. S. Wooster, pp. 183-193, National Academy of Science, Washington, D. C., 1970.

Levitus, S., Climatological atlas of the world ocean, NOAA Professional Paper 13, U.S. Government Printing Office, Washington, D. C., 173 pp., 1982.

Lewis, M. R., W. G. Harrison, N. S. Oakey, D. Hebert, and T. Platt, Vertical nitrate fluxes in the oligotrophic ocean, Science, 234, 870-873, 1986.

Lewis, S., and A. Nir, On tracer theory in geophysical systems in the steady and non-steady state, part II, Non-steady statetheoretical introduction, Tellus, 30, 260-271, 1978.

Luyten, J. L., J. Pedlosky, and H. Stommel, The ventilated thermocline, J. Phys. Oceanogr., 13, 292-309, 1983.

Martin, J. H., G. A. Knauer, D. M. Karl, and W. W. Broenkow, VERTEX: carbon cycling in the northeast Pacific, Deep Sea Res., 34, 267-286, 1987.

Minster, J.-F., and M. Boulahdid, Redfield ratios along isopycnal 
surfaces-A complementary study, Deep Sea Res., 34, 1981-2003, 1987.

Musgrave, D. L., Numerical studies of tritium and helium-3 in the thermocline, J. Phys. Oceanogr., 20, 344-373, 1990.

Musgrave, D. L., J. Chou, and W. J. Jenkins, Application of a model of upper-ocean physics for studying seasonal cycles of oxygen, J. Geophys. Res., 93, 15,679-15,700, 1988.

Najjar, R. C., Simulations of the phosphorus and oxygen cycles in the world ocean using a general circulation model, Ph.D. thesis, Princeton Univ., Princeton, N. J., 1990.

Nir, A., On the interpretation of tritium "age" measurements of groundwater, J. Geophys. Res., 69, 2589-2595, 1964.

Nir, A., and S. Lewis, On tracer theory in geophysical systems in the steady and non-steady state, part I, Tellus, 27, 372-382, 1975.

Peng, T.-H., T. Takahashi, and W. S. Broecker, Seasonal variability of carbon dioxide, nutrients and oxygen in the northern North Atlantic surface water: Observations and a model, Tellus, Ser. B, 39B, 439-458, 1987.

Platt, T., W. G. Harrison, M. R. Lewis, W. K. W. Li, S. Sathyendranath, R. E. Smith, and A. F. Vezina, Biological production of the oceans: The case for a consensus, Mar. Ecol. Prog. Ser., 52, 77-88, 1989.

Riley, G. A., Oxygen, phosphate, and nitrate in the Atlantic Ocean, Bull. Bingham Oceanogr. Coll., 127 pp., 1951.

Rintoul, S., and C. Wunsch, Mass, heat, oxygen, and nutrient fluxes and budgets in the North Atlantic Ocean, Deep Sea Res., in press, 1990.

Sarmiento, J. L., A tritium box model of the North Atlantic thermocline, J. Phys. Oceanogr., 13, 1269-1274, 1983.

Sarmiento, J. L., and E. Gwinn, Strontium 90 fallout prediction, $J$. Geophys. Res., 91, 7631-7646, 1986.

Sarmiento, J. L., and J. R. Toggweiler, A new model for the role of the oceans in determining atmospheric $\mathrm{P}_{\mathrm{CO}_{2}}$, Nature, 308, 621-624, 1984.

Sarmiento, J. L., C. G. H. Rooth, and W. Roether, The North Atlantic tritium distribution in 1972, J. Geophys. Res., 87, 8047-8056, 1982.

Sarmiento, J. L., J. R. Toggweiler, and R. Najjar, Ocean carboncycle dynamics and atmospheric $\mathrm{P}_{\mathrm{CO}_{2}}$, Philos. Trans. $R$. Soc. London, Ser. A, 325, 3-21, 1988.

Shulenberger, E. L., and J. L. Reid, The Pacific shallow oxygen maximum, deep chlorphyll maximum, and primary productivity, reconsidered, Deep Sea Res., 28A, 901-919, 1981.

Siegenthaler, U., and T. Wenk, Rapid atmospheric $\mathrm{CO}_{2}$ variations and ocean circulation, Nature, 308, 624-626, 1984.

Spitzer, W. S., and W. J. Jenkins, Rates of vertical mixing, gas exchange and new production: Estimates from seasonal gas cycles in the upper ocean near Bermuda, J. Mar. Res., 47, 169-196, 1989.

Sugimura, Y., and Y. Suzuki, A high-temperature catalytic oxidation method of non-volatile dissolved organic carbon in seawater by direct injection of liquid samples, Mar. Chem., 24, 105-231, 1988.

Suzuki, Y., Y. Sugimura, and T. Itoh, A catalytic oxidation method for for the determination of total nitrogen dissolved in seawater, Mar. Chem., 16, 83-97, 1985.

Thiele, G., and J. L. Sarmiento, Tracer dating and ocean ventilation, J. Geophys. Res., 95, 9377-9391, 1990.

Toggweiler, J. R., Deep-sea carbon, a burning issue, Nature, 334 , 468, 1988.

Toggweiler, J. R., Is the downward dissolved organic matter (DOM) flux important in carbon transport?, in Productivity of the Ocean: Past and Present, Dahlem Workshop Report, edited by W. H. Berger, V. Smetacek, and D. Wefer, pp. 65-84, John Wiley, New York, 1989.

Williams, P. M., and E. R. M. Druffel, Dissolved organic matter in the ocean: Comments on a controversy, Oceanography, 1, 14-17, 1988.

Wolberg, J. R., Prediction Analysis, 221 pp., D. Van Nostrand, Princeton, N. J., 1967.

R. M. Key and J. L. Sarmiento, Atmospheric and Oceanic Sciences Program and Department of Geology and Geophysics, Princeton University, Princeton, NJ 08544.

G. Thiele, Deutsche Forschungs- und Versuchasanstalt für Luftund Raumfahrt, Astronautenburo, Linder Hohe, D-5000 Köln 90, Federal Republic of Germany.

W. S. Moore, Department of Geology, University of South Carolina, Columbia, SC 29208.

(Received August 17, 1989; revised January 8, 1990; accepted April 14, 1990.) 